\title{
Recommendation of RILEM TC 261-CCF: test method to determine the flexural creep of fibre reinforced concrete in the cracked state
}

\author{
A. Llano-Torre $\mathbb{D} \cdot$ P. Serna $(\mathbb{C}$
}

Received: 6 November 2020/ Accepted: 5 March 2021/Published online: 21 May 2021

(C) The Author(s) 2021

\begin{abstract}
To date there is no clear consensus about how creep of cracked FRC structural elements should be considered. In recent years, different methodologies have been developed for multiple stress cases. The absence of a standardised methodology to evaluate flexural creep in the cracked state has hindered general comparisons and conclusions that could lead to significant advances in this topic. Since 2014, the study of the creep behaviour of cracked FRC has been coordinated by the RILEM TC 261-CCF. All the
\end{abstract}

\section{TC Membership}

Chairman: P. Serna, Spain, Universitat Politècnica de

València, Valencia.

Secretary: S.H.P. Cavalaro, UK, Loughborough University, Loughborough.

Members: B. Barragan, France; E.S. Bernard, Australia; W.P. Boshoff, South Africa; N. Buratti, Italy; T. Clarke, Australia; V. Dao, Australia; M. di Prisco, Italy; E. Garcia-Taengua, UK; R. Gettu, India; C. Larive, France; A. Llano-Torre, Spain; C. Mazzotti, Italy; S. Moro, Italy; T. Nishiwaki, Japan; B. Parmentier, Belgium; H. Pauwels, Belgium; S.H.P. Cavalaro, UK; G. Plizzari, Italy; C. del Prete, Italy; K.A. Rieder, USA; D. Rogat, France; P. Rossi, France; K. Santos, Brazil; P. Serna, Spain; R.D. Toledo Filho, Brazil; L. Vandewalle, Belgium; G. Vitt, Belgium; R. Vrijdaghs, Belgium; S. Wolf, Luxemburg; R. Zerbino, Argentina;

Other contributors: W. Kusterle, Germany; J. Bokern, Germany.

\section{A. Llano-Torre $(\varangle) \cdot$ P. Serna}

Institute of Concrete Science and Technology ICITECH, Universitat Politècnica de València, Valencia, Spain

e-mail: aillator@upv.es available creep methodologies were analysed in terms of procedure, equipment and results. A comprehensive Round-Robin Test (RRT) on the creep behaviour of cracked sections of FRC was proposed and undertaken by a total of 19 participant laboratories from 14 countries all over the world. The analysis and conclusions of the RRT results and the different methodologies provided the basis for this recommendation. This recommendation focuses on the test method to evaluate the flexural creep of FRC specimens in the cracked state. Guidelines on specimen production, detailed test equipment, experimental setup and test procedure as well as the definitions of the most relevant parameters are provided.

Keywords Fibre reinforced concrete $\cdot$ Creep $\cdot$ Longterm behaviour $\cdot$ Flexural creep $\cdot$ Cracked state

\section{Introduction}

Although the use of fibre reinforced concrete (FRC) is widespread in some fields of civil engineering, there is no consensus about how to consider the creep of

P. Serna

e-mail: pserna@cst.upv.es 
cracked FRC structural elements to date. The effects of the long-term deformations of FRC in the cracked state have not been included in design codes yet.

The first methodologies for characterising the flexural creep behaviour were developed for both individual and multi- specimen setups [1-4] and for different sizes of specimens. In recent years, the interest in the long-term behaviour of FRC in the cracked state has significantly increased. Several methodologies have been developed for multiple loading configurations and specimen sizes: flexure [5-8], direct tension [9-11], structural beams [12], round panels [13] and square panels [14, 15]. Although these methodologies have been designed for standard FRCs, some of these methodologies have been applied to both standard FRC [16] and UHPFRC [17] specimens. To date, the most prevalent methodology for creep characterisation is the flexural creep test for prismatic specimens. Unfortunately, the absence of a standardised methodology for the evaluation of flexural creep in the cracked state has hindered global comparisons and conclusions that could lead to significant advances in this topic.

Since 2014, the study of creep behaviour of cracked FRC has been coordinated by the RILEM TC 261-CCF. All the available creep methodologies were analysed in terms of procedure, equipment and results. The first ever workshop which focused exclusively on the creep behaviour of cracked FRC was held in 2016 [18], signalling an increasing interest in creep. A comprehensive Round-Robin Test (RRT) on creep of FRC cracked sections was launched in 2015 [19]. The participation of 19 laboratories across 20 institutions in 14 countries all over the world, enabled the realisation of the largest experimental campaign on creep in the cracked state. As a result of the RRT, an extensive database of creep test results was created based on a published proposal [20] presented to the TC, containing comprehensive information from 124 cracked FRC specimens tested using different creep testing procedures in agreed conditions. The analysis and conclusions of the RRT results and the different methodologies performed served as basis for this recommendation.

This recommendation focuses on the test method to determine the flexural creep of FRC specimens in the cracked state. The procedure described in this recommendation is based on applying sustained flexural stresses to cracked FRC specimens and registering the time-dependent crack opening deformation. Guidelines on the production of specimens, detailed test equipment and creep frames construction, experimental setup and test procedure are provided along with the definition of the most relevant parameters.

This RILEM Recommendation was prepared by the RILEM TC 261-CCF 'Creep behaviour in Cracked Sections of Fibre Reinforced Concrete' based on the results obtained in an international Round-Robin Test program and assessed on FRC mixes with minimum structural performance requirements. The RoundRobin Test report will soon be published within the RILEM State-of-the-Art Reports (STAR) BookSeries by Springer [21].

\section{Scope}

It is the aim of this recommendation to describe a method for determining the flexural creep due to sustained loading of FRC specimens in their cracked state. The time-dependent crack mouth opening displacement (CMOD) values in the cracked state are determined from test data.

This recommendation is intended for comparative analysis of time-dependent behaviour of different FRCs. The results or parameters derived from the application of this recommendation shall not be directly used for structural applications since the required creep formulation applicable to FRC structural design has not been developed yet.

Tertiary creep (creep rupture), impact of exposure to different temperatures on the long-term deflections or the identification of long-term material properties for design purposes are out of the scope of this recommendation. If specific scenarios, out of the scope of the recommendation, shall be investigated, related parameters such as creep index or pre-cracking level can be modified.

This recommendation is applicable to standard FRC notched specimens that reveals a single crack when tested in flexure in compliance with EN 14651. Multiple cracking is also considered if all cracks start from the tip of the notch. If the single crack occurs out of the tip of the notch, the FRC specimens are out of this recommendation. 


\section{Referenced standards}

The following standards are applicable within the scope of this Recommendation:

EN 14651:2005 + A1:2007. Test Method for Metallic Fibre Concrete-Measuring the Flexural tensile Strength (Limit of Proportionality (LOP), Residual).

ASTM C1609/C1609M-19, Standard Test Method for Flexural Performance of fiber-reinforced concrete (Using Beam With Third-Point Loading).

ISO 7500-1:2018, Metallic materials-Calibration and verification of static uniaxial testing machinesPart 1: Tension/compression testing machines-Calibration and verification of the force-measuring system.

\section{Glossary}

This list presents the notation of crack mouth opening displacement (CMOD) parameters. Analogous notation is applicable to deflection $(\delta)$ parameters by replacing CMOD by $\delta$.

CMOD: crack mouth opening displacement

COD: crack opening displacement

$\delta$ : deflection

CTOD: crack tip opening displacement

DAS: data acquisition system

$\mathrm{CMOD}_{\mathrm{pn}}$ : target nominal CMOD in the pre-cracking stage

$\mathrm{CMOD}_{\mathrm{p}}$ : maximum CMOD reached in the precracking stage

$\mathrm{CMOD}_{\text {pri }}$ : residual CMOD measured immediately after unloading at the end of the pre-cracking stage $\mathrm{CMOD}_{\mathrm{pr}}$ : residual CMOD measured 10 minutes after unloading at the end of the pre-cracking stage $\mathrm{CMOD}_{\mathrm{ci}}$ : instantaneous CMOD immediately after reaching the reference load

$\mathrm{CMOD}_{\mathrm{ci}}{ }^{15}$ : short-term CMOD deformation 15 minutes after beginning to apply the load in the creep frame

$\mathrm{CMOD}_{\mathrm{cd}}{ }^{\mathrm{j}}$ : delayed CMOD after $j$ days in the creep test

$\mathrm{CMOD}_{\mathrm{ctm}}^{\mathrm{j}}$ : total CMOD measured after $j$ days in the creep test (sum of $\mathrm{CMOD}_{\mathrm{ci}}{ }^{15}$ and delayed CMOD) $\mathrm{CMOD}_{\mathrm{ct}}{ }^{\mathrm{j}}$ : total CMOD after $j$ days from onset of loading corrected with the shrinkage effect
$\mathrm{CMOD}_{\mathrm{cs}}{ }^{\mathrm{j}}$ : shrinkage CMOD deformations after $j$ days from onset of loading $\mathrm{CMOD}_{\text {cri: }}$ : residual CMOD recovery immediately after unloading at the end of the creep test

$\mathrm{CMOD}_{\text {crd}}$ : residual CMOD recovery 30 days after unloading at the end of the creep test

$\mathrm{CMOD}_{\mathrm{oi}}{ }^{15}$ : absolute short-term CMOD assessed from the origin of deformations (Point $\mathrm{O}$ in Fig. 8) $\mathrm{CMOD}_{\mathrm{o}}{ }^{\mathrm{j}}$ : absolute CMOD after $j$ days assessed from the origin of deformations (Point $\mathrm{O}$ in Fig. 8) $\varphi_{\mathrm{w}, \mathrm{c}}^{\mathrm{j}}$ : crack opening creep coefficient referring to creep stage at $\mathrm{j}$ days

$\varphi_{\mathrm{w}, \mathrm{o}}{ }^{\mathrm{j}}$ : crack opening creep coefficient referring to origin at $\mathrm{j}$ days

$\mathrm{CMOD}_{y}$ : crack mouth opening displacement measured at a $y$ distance from bottom of the specimen

$y$ : distance between the bottom of the specimen and the line of measurement

$h$ : height of the specimen

$h_{\mathrm{sp}}$ : distance between the tip of the notch and the top of the test specimen in the mid-span section

$M$ : bending moment

$M \mathrm{j}$ : bending moment value for different crack opening levels $j=1,2,3$ or 4 in compliance with EN 14651

$b$ : width of test specimen

$f_{\mathrm{R}, \mathrm{j}}$ : residual flexural tensile strength for different crack opening levels $j=1,2,3$ or 4 in compliance with EN 14651

$L$ : length of the specimen

$l$ : clear span between supports in flexural test

$l_{a}$ : distance between support and nearest loading point in four-point bending test (4PBT) setup

$l_{b}$ : span between loading points in 4PBT flexural test

$f_{\mathrm{L}}$ : residual flexural tensile strength at the limit of proportionality (LOP)

$f_{\mathrm{R}, 1}$ : residual flexural tensile strength corresponding to $\mathrm{CMOD}_{1}=0.5 \mathrm{~mm}$

$f_{\mathrm{R}, 3}$ : residual flexural tensile strength corresponding to $\mathrm{CMOD}_{3}=2.5 \mathrm{~mm}$

$f_{\text {PostCreep,R,2: }}$ : residual flexural tensile strength corresponding to origin at $\mathrm{CMOD}_{2}=1.5 \mathrm{~mm}$

$f_{\text {PostCreep,R,3: }}$ residual flexural tensile strength corresponding to origin at $\mathrm{CMOD}_{3}=2.5 \mathrm{~mm}$

$f_{\text {PostCreep, R,4: }}$ residual flexural tensile strength corresponding to origin at $\mathrm{CMOD}_{4}=3.5 \mathrm{~mm}$ $f_{\mathrm{R}, \mathrm{p}}$ : residual flexural tensile strength at $\mathrm{CMOD}_{\mathrm{p}}$ $f_{\mathrm{R}, \mathrm{c}}$ : stress applied during the creep stage 
$F_{\mathrm{c}}$ : load applied to the specimen during the creep stage

$F_{\mathrm{L}}$ : load at the limit of proportionality (LOP)

$F_{1}$ : load corresponding to $\mathrm{CMOD}_{1}=0.5 \mathrm{~mm}$

$F_{\text {PostCreep,2: }}$ load corresponding to $\mathrm{CMOD}_{2}=1.5$ $\mathrm{mm}$

$F_{\text {PostCreep,3: }}$ load corresponding to $\mathrm{CMOD}_{3}=2.5$ $\mathrm{mm}$

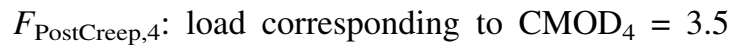
$\mathrm{mm}$

$t_{c i}$ : duration of the loading process in the creep test

$t_{c r i}$ : duration of the unloading process in the creep test

$t_{c r d}$ : duration after unloading of the creep test in which recovery was registered

$I_{n}$ : nominal creep index or stress level as percentage of $f_{\mathrm{R}, \mathrm{p}}$

$I_{c}$ : applied creep index or stress level as the ratio $I_{c}=$ $f_{\mathrm{R}, \mathrm{c}} / f_{\mathrm{R}, \mathrm{p}}$

$n_{f}$ : average number of fibres per unit of fracture surface area $\left(\right.$ fibres $\left./ \mathrm{cm}^{2}\right)$

\section{Test specimens}

\subsection{Geometry}

Prismatic test specimens conforming to EN 14651 shall be used. The nominal cross-section shall be $150 \times 150 \mathrm{~mm}$. The specimen length $L$ shall be not lower than $550 \mathrm{~mm}$ and not higher than $700 \mathrm{~mm}$.

The specified test specimen dimensions are appropriate as long as the maximum aggregate size is not larger than $32 \mathrm{~mm}$ and the fibres are not longer than $60 \mathrm{~mm}$.

\subsection{Fibre dosage}

There is no minimum or maximum requirement regarding the FRC performance and fibre dosage. However, this recommendation was assessed on FRC mixes for structural applications, which showed only one crack in flexural tests according to EN 14651.

\subsection{Casting, curing and storage}

Test specimens shall be cast and cured in compliance with EN 14651. After being notched, the test specimens shall be cured for a minimum of 3 days until no more than $3 \mathrm{~h}$ before pre-cracking, allowing enough time for preparation, including the positioning of transducers. The pre-cracking test shall be performed at the age of 28 days in compliance with EN 14651.

After pre-cracking and prior to testing in creep, the specimen shall be stored for at least 7 days in the climate chamber with controlled environmental conditions where the creep test is to be conducted. Creep testing shall normally start at the age of 35 days.

The RILEM Technical Committee 261-CCF recommends the following schedule for testing in creep:

- Day 0: Specimens production

- Day 1: Specimens are demoulded and located in the curing room

- Day 25: Specimens are notched and returned to curing room

- Day 28: Specimens are pre-cracked and stored in the climate room of creep test

- Day 35: Start of creep test

\subsection{Notching of test specimens}

The use of notched specimens in compliance of the EN 14651 reference standard is recommended. The notch dimensions as well as the notching procedure are defined in EN 14651.

Alternatively, un-notched specimens sized $150 \times 150 \times 500 \mathrm{~mm}$ are also supported in this recommendation following the ASTM C1609/ C1609M standard.

\section{Creep test equipment}

\subsection{Environmental conditions}

Due to the significance of the temperature and relative humidity on the long-term behaviour of FRC (both creep and shrinkage), the flexural creep test shall be carried out in a climate-controlled room. The location of the creep frames in isolated testing rooms is a good way to stabilize the environmental conditions but it is not enough: temperature and relative humidity shall be controlled and not just measured or restricted. The use of thermal and hygrometric equipment is crucial to 
ensure that the climate conditions are well controlled and kept within the acceptable ranges.

If creep tests are performed in a laboratory environment, climate or isolated room without hygrometric and temperature control equipment, the climatic conditions shall be reported merely as "restricted", but not "controlled".

The recommended temperature during creep test is $20{ }^{\circ} \mathrm{C} \pm 2^{\circ} \mathrm{C}$. Regarding the relative humidity, the recommended relative humidity in the room during creep test shall have a target value between 50 and $70 \%$ and shall remain stable within $\mathrm{a} \pm 5 \%$ range (e.g., from 55 to $65 \%$ if the target value is $60 \%$ ) (see Fig. 20).

If either the temperature or the relative humidity falls outside the acceptable range of variation, it shall be stated in the report. If the acceptable threshold is exceeded for more than 10 days in a row, the specimens should be marked as "Tested out of recommended range" in the test report and disregarded from any subsequent analysis.

\subsection{Creep testing frame}

The construction of creep frames for testing creep shall adhere to the following specifications regarding the materials, boundary conditions and configuration to guarantee verticality and a constant load during the test.

The specimens shall be tested individually or in a multi-specimen setup (with up to three specimens tested simultaneously) to increase the number of tested specimens per frame.

The load shall be applied by means of a seconddegree lever arm as depicted in Fig. 1. Even though both lever arm positions are acceptable, an upper lever arm (a) with compressive transmission load is preferable to a lower lever arm frame (b). In the case of upper lever arm creep frames, the arm lays directly on the top specimen and the load depends only on the counterweight and the lever arm multiplier factor, giving a more stable load over time. Moreover, the loading procedure for the upper lever arm setup is easier reducing the time in which the load is applied, which is crucial for the creep coefficient calculation. In the case of lower lever arm frames, additional load transfer elements such as screwed bars, nuts and other connectors are required to carry the load from the counterweight to the top specimen. When using so many load transfer elements, more time for preparation is required and small differences such as nuts torque, may significantly influence the required load and consequently the applied stress over time. In both cases, the lever arm shall be placed as close to horizontal as possible at the beginning of the creep test to minimise the effect of horizontal loads.

The use of emergency brakes for any unexpected collapse is highly recommended. Otherwise, both the counterweight and the specimens may fall and cause damage to the equipment.

\subsubsection{Load configuration}

The load configuration used in the creep frames can be either 3PBT (Three-point bending test) or 4PBT (Four-point bending test) depending on the setup configuration. In the case of single specimen setup, the 3PBT is recommended as seen in Fig. 2a following the EN 14651 load configuration. In the case of multispecimen setup, the 4PBT flexure configuration is recommended (Fig. 2b) to improve the stability. Both recommended 3PBT and 4PBT load configurations are defined in terms of supports and loading points span in Fig. 2. Any variation to the clear span $(l)$ or load supports span $\left(l_{b}\right)$ values shall be clearly stated in the test report.

Since the target of the creep test is to apply a certain stress over time, it is important to obtain the required load to be applied by means of the right equation depending on the flexural setup adopted. In the case of 3PBT loading configuration, the flexural residual strength shall be obtained according to the EN 14651 equation:

$M=\frac{F}{2} \cdot \frac{l}{2}=\frac{F l}{4}$ where $f_{\mathrm{R}, \mathrm{j}}=\frac{6 M_{\mathrm{j}}}{b h_{\mathrm{sp}}^{2}}=\frac{3 F_{\mathrm{j}} l}{2 b h_{\mathrm{sp}}^{2}}$

In the case of using the 4PBT adapted load configuration in multi-specimen setup during the creep stage, the flexural residual strength calculation shall be adapted into the following equation:

$M=\frac{F}{2} \cdot \frac{l}{3}=\frac{F l}{6}$ where $f_{\mathrm{R}, \mathrm{j}}=\frac{6 M_{\mathrm{j}}}{b h_{\mathrm{sp}}^{2}}=\frac{F_{\mathrm{j}} l}{b h_{\mathrm{sp}}^{2}}$

where $F$ is the total applied load.

The load configuration systems chosen for both precracking and creep tests shall be stated in the report. 


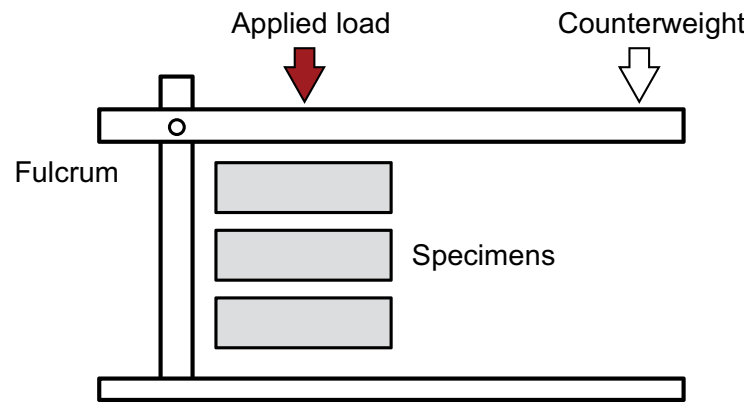

(a)

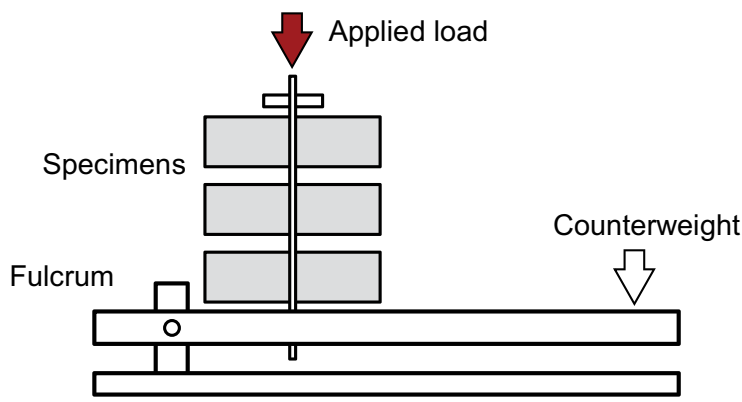

(b)

Fig. 1 Creep frame scheme options: a creep frame with upper lever arm and compressive transmission load and $\mathbf{b}$ creep frame with lower lever arm and tensile transmission load.

\section{EN 14651 3PBT set-up}

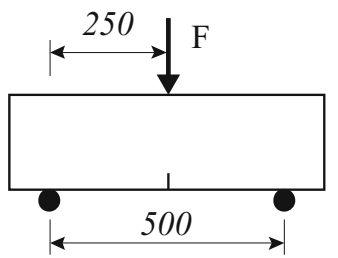

(a)
4PBT adapted set-up

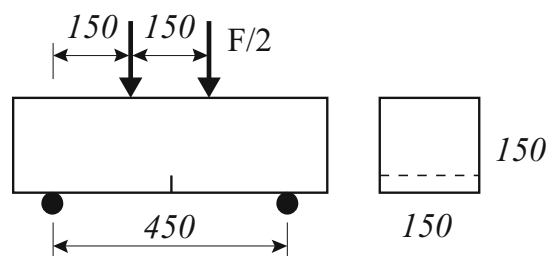

(b)

Fig. 2 Recommended flexure load configurations: a EN 14651 3PBT flexural setup and b 4PBT adapted set-up.

\subsubsection{Single or multi-specimen}

A single specimen test setup is recommended since it requires a simpler procedure due to the fewer intervening elements. However, single specimen setups also require more creep frames and testing area in the facilities. Therefore, the multi-specimen setups are also accepted to increase the efficiency if the recommended conditions are assured.

In the multi-specimen configuration, it shall be ensured that the individual deformation or sudden collapse of one specimen does not compromise the stability of the rest of the specimens, the load in the frame or the continuity of the creep test for the remaining specimens. In order to avoid this influence between the specimens, load transfer plates shall be located between the specimens and thus provide a certain independence to the specimens. The load transfer plates carry the load and supporting rollers and, if possible, steel blocks as emergency brakes that may stop a broken specimen before the collapse.

The recommended setups for both single and multispecimen options, (a) and (b) respectively, are presented in Fig. 3. Alternatively, the setups (c) and (d) can be also accepted. In the case of ASTM configuration (d), shall only be accepted for single specimen setup.

The recommendation of using transfer plates between specimens makes test setups with inverted specimens irrelevant. Therefore, in all cases it is recommended to place all the specimens with the notch at the bottom face as seen in Fig. 3. Inverted specimens as shown in Fig. 4 are not recommended since crack propagation or recovery could be blocked if detached concrete small pieces falls into the notch. Multi-specimen configurations without transfer plates such as those in Fig. 4 are not recommended since the boundary conditions cannot be assured without wellconstructed supports.

It is important to highlight that, in the case of a multi-specimen setup, the weight of different rollers, plates, brakes and any other elements shall be considered as additional load applied onto the specimens below. Table 1 specifies the elements that shall be considered in the calculation of the real applied load for each specimen, at the corresponding position, 


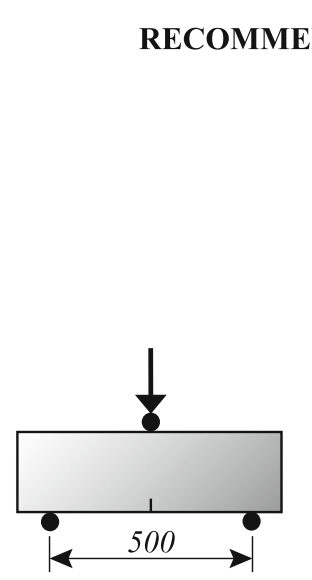

(a) 3PBT Single setup

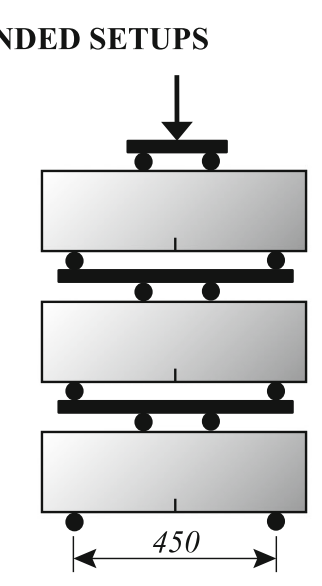

(b) 4PBT Multi (3) setup

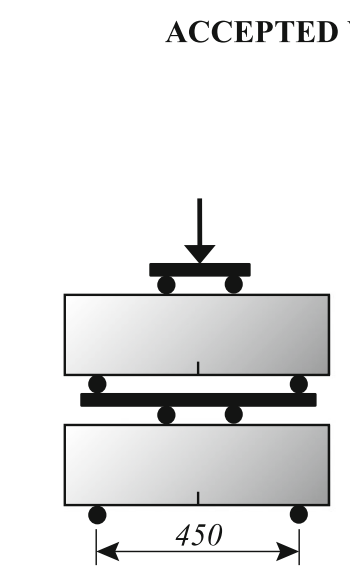

(c) 4PBT Multi (2) setup

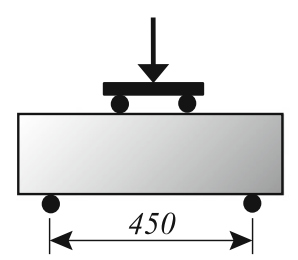

(d) ASTM C1609

Fig. 3 Recommended creep test set-ups

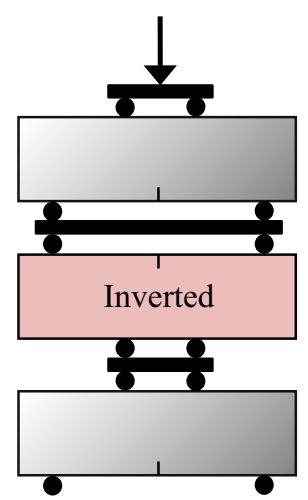

(a)

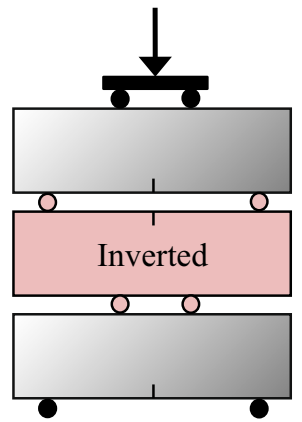

(b)

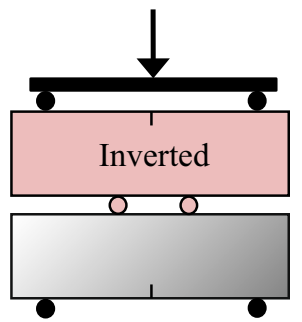

(c)

Fig. 4 Not recommended creep test configurations

where a schematic of the multi-specimen setup has been included identifying all the elements. Note that the transfer plate self-weight includes the self-weight of the load and supporting rollers.

The duration of stacking the specimens shall not exceed $30 \mathrm{~min}$. Depending on the FRC performance and the creep index, the deadload of the upper specimens and transmission elements shall represent a certain load percentage of the required sustained stress $f_{\mathrm{R}, \mathrm{c}}$ not larger than $15 \%$. The multi-specimen setup shall assure that the bottom specimen will not exceed the $15 \%$ of the expected sustained stress $f_{\mathrm{R}, \mathrm{c}}$, at any step of the recommended creep procedure. Therefore, if mounting a three-specimens column, the deadload of the bottom specimen when stacked unloaded will exceed the $15 \%$ of $f_{\mathrm{R}, \mathrm{c}}$, then only two specimens shall be mounted in the frame for the creep test to assure this condition.

\subsubsection{Support boundary conditions}

In the Round-Robin Test report performed by the RILEM TC 261-CCF [21], a classification of the different support boundary conditions was defined. This classification is based on the three degrees of freedom shown in Fig. 5: (I) rotation around the $X$ axis, (II) rotation around the $Z$ axis, and (III) displacement along the $X$ axis. The $X$ axis corresponds to the longitudinal axis of the specimens. 
Table 1 Elements to be considered in the load calculation

Fig. 5 Classification of the degrees of freedom of supports

\begin{tabular}{|c|c|c|c|c|}
\hline \multirow[t]{2}{*}{ Element self-weight } & \multicolumn{3}{|c|}{ Specimen } & \\
\hline & Top & Middle & Bottom & \\
\hline a) Applied load F & $X$ & $\mathrm{X}$ & $\mathrm{X}$ & $\rightarrow \mathrm{F} \perp$ \\
\hline b) Load transfer plate and rollers & $X$ & $\mathrm{X}$ & $\mathrm{X}$ & 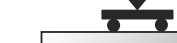 \\
\hline c) Top specimen weight & - & $\mathrm{X}$ & $\mathrm{X}$ & c) $\longrightarrow$ Top \\
\hline d) Transfer plate and rollers & - & $\mathrm{X}$ & $\mathrm{X}$ & \\
\hline e) Middle specimen weight & - & - & $\mathrm{X}$ & e) $\longrightarrow$ Middle \\
\hline \multirow[t]{2}{*}{ f) Transfer plate and rollers } & - & - & $\mathrm{X}$ & \\
\hline & & & & Bottom \\
\hline
\end{tabular}

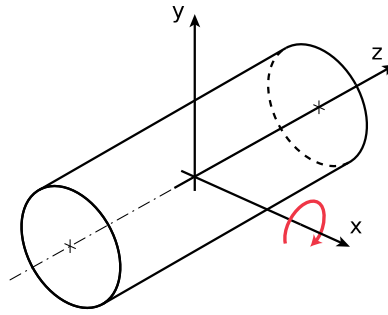

1

Rotation in X

Fig. 6 Recommended degrees of freedom for the roller support

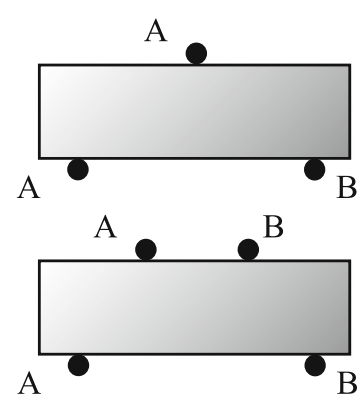

A

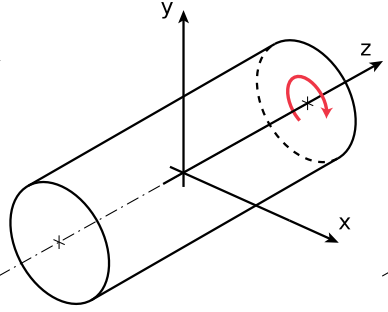

II

Rotation in Z

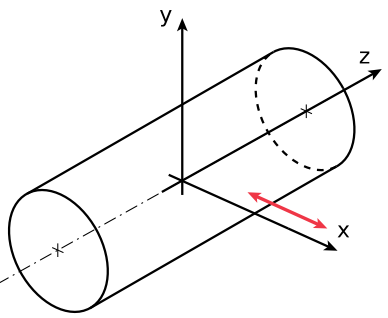

III
Position

Top:

Bottom:

Top:

Bottom:
Roller A

OOX

OOX

$\mathrm{XOX}$

OOX
Roller B<smiles>[TlH]</smiles>

XOX

OOX

XOX
Different support conditions are defined by a threeletter symbol, each letter corresponding to each of the abovementioned degrees of freedom. Each letter can be either $\mathrm{X}$ (restrained) or $\mathrm{O}$ (unrestrained, free movement). Considering this classification and the conclusions presented in the RRT report, the recommended support conditions for each load configuration alternatives are defined in Fig. 6.

This recommendation aims to define the recommended support boundary conditions by classifying the degrees of freedom restrained. The supports for the creep test shall be constructed in compliance with these restrictions recommendations and assure the support conditions during the creep test duration. The ASTM C1812 [22] standard provides instructions for support construction that can be used as reference.

\subsection{Transducers and electronic devices}

\subsubsection{CMOD or deflection}

The CMOD or deflection evolution through time shall be measured and recorded throughout the creep test duration. For this purpose, two different types of electronic transducers are recommended: clip gauges and linear variable displacement transducers 
(LVDTs). The use of Pi-shape displacement transducers is acceptable in the same conditions as the clip gauges. The use of DEMEC gauge studs or dial gauges is not recommended.

In the case of creep test setups described in Fig. 3 with notched specimens, it is highly recommended to measure the CMOD according to EN 14651. Although direct CMOD measurement with clip gauge is preferred, the use of LVDTs is highly extended and accepted if the proper conversion is done. Alternatively, in those cases where deflection $(\delta)$ is measured instead of CMOD, deflection values shall be converted to CMOD values in compliance with EN 14651.

On the contrary, if the creep setup to be performed is in Fig. 3d with unnotched specimens, deflection shall be measured according to ASTM C1609 since the CMOD cannot be measured.

Clip gauge displacement transducers shall be mounted under the specimen across the notch mouth, parallel to the longitudinal axis of the specimen and centred over its width, such that the distance $y$ between the bottom of the specimen and the line of measurement is $5 \mathrm{~mm}$ or less.

When LVDTs are used, the distance between the two measuring points shall not exceed $50 \mathrm{~mm}$, as shown in Fig. 7. The transducers shall be mounted under the specimen, parallel to its longitudinal axis and centred along its width, such that the distance $y$ between the bottom of the specimen and the line of measurement is less than $20 \mathrm{~mm}$. LVDTs shall have a resolution of at least $0.001 \mathrm{~mm}$ and the maximum permissible error shall be $\pm 0.005 \mathrm{~mm}$.

As per EN 14651, in those cases where the line of measurement is placed at a distance $y$ from the bottom surface of the specimen, the CMOD value shall be determined from the measured $\mathrm{CMOD}_{y}$ value by means of the following equation:

$\mathrm{CMOD}=\mathrm{CMOD}_{y} \cdot\left(\frac{h}{h+y}\right)$

The use of a data acquisition system (DAS) for a continuous reading is recommended. For both loading and unloading phases, the recommended recording rate for CMOD is one reading per second $(1 \mathrm{~Hz})$ to a proper definition of the loading and unloading section plot. Moreover, this recording rate provides useful information for the understanding of any unusual or sudden deformations and how fast and steady is the load applied. The recommended recording rate for the CMOD values during the long-term test phase is one reading every 1800 s.

In those cases where the transducers are not continuously connected to a DAS during the creep test, deformation shall be manually registered in compliance with the minimum reporting ages stated in Sect. 7.2.5, at least at 6 and $12 \mathrm{~h}, 1,2,3,5,7,14$ and 30 days for the first month and once a month (in 30 days lapses) until the end of the creep test.

\subsubsection{Temperature and relative humidity}

Temperature and humidity measurement devices are required in the climate room to monitor and record the evolution of the environmental conditions during the creep test. It is recommended to connect the Temperature and humidity measurement devices to the DAS for a continuous recording. The recommended recording rate for the temperature and relative humidity
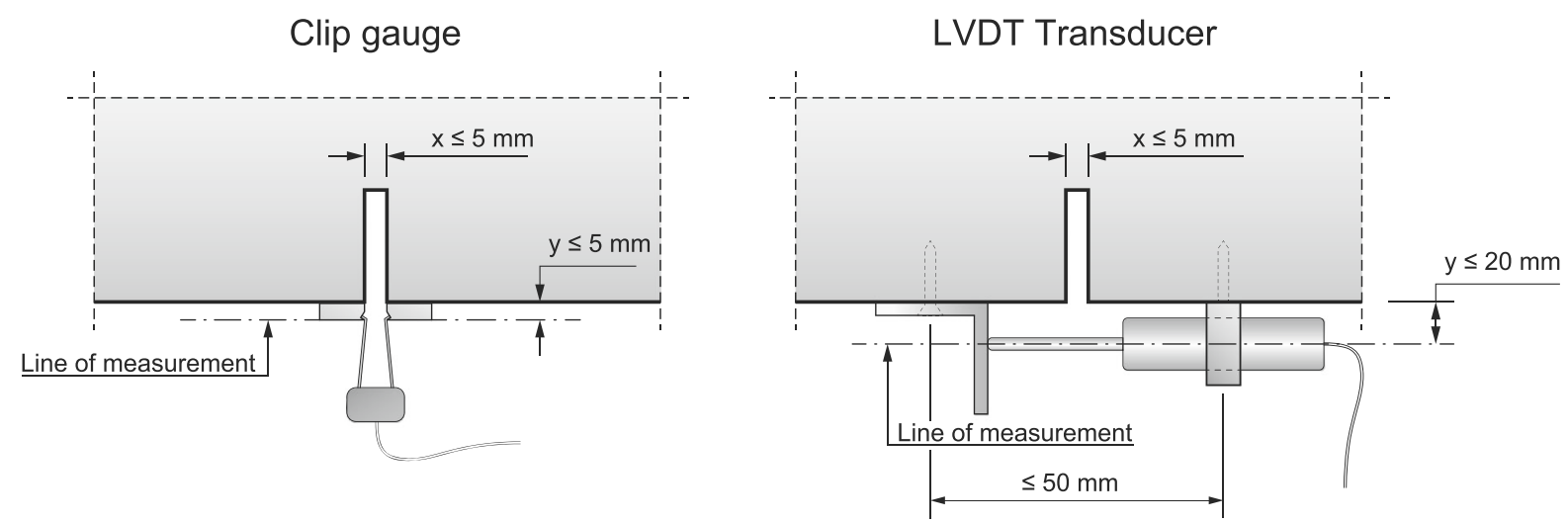

Fig. 7 LVDT location and measuring points distance 
values during the creep test is one reading every 1800 s as recommended for CMOD measurement. If on the contrary, the measurement device is not connected to a DAS, both temperature and relative humidity shall be manually registered twice a day (day/night) which corresponds to the minimum environmental conditions reporting ages. Thus, the evolution of environmental conditions can be plotted as required.

A figure showing the evolution of both temperature and relative humidity over time with two readings per day (day/night) during the entire creep test duration shall be included in the test report as explained in Sect. 8.3. A sample of environmental conditions evolution figure is illustrated in Fig. 20.

\section{Test procedure}

The general test procedure can be divided in three main stages: pre-cracking stage (O-D), creep stage (D$\mathrm{H})$ and post-creep stage $(\mathrm{H}-\mathrm{K})$, as shown in Fig. 8.

\subsection{Pre-cracking stage}

\subsubsection{Preparation of specimens}

The specimens shall be prepared and positioned for pre-cracking under flexure following the setup in EN 14651.

In the case of multi-specimen creep test setup, depending on the number of specimens to be tested simultaneously in the frame, it is highly recommended to pre-crack more specimens of the same mix than strictly required so that the best subset of specimens with minimum creep index variation can be selected. Table 2 below defines the recommended minimum number of specimens to pre-crack depending on the specimens simultaneously tested in the creep frame to avoid relevant creep index scatter.

The pre-cracked specimens not intended for testing in the creep frame can be used as reference specimens for shrinkage control, as explained in Sect. 7.3. Any extra specimens not needed for either the creep or the shrinkage tests can be stored as backup specimens. Backup specimens shall be stored in the creep test ambient conditions and supported on their side (turned $90^{\circ}$.

\subsubsection{Pre-cracking test}

The flexural pre-cracking tests shall follow the 3PBT load configuration in compliance with EN 14651 and transducers shall be located in compliance with Fig. 7 limitations. Specimens shall be pre-cracked according to ASTM C1609/C1609M only in those cases where the load configuration shown in Fig. 3d) is the one selected for the creep tests.

In the case of testing machines where the CMOD is controlled, a constant CMOD rate of $0.05 \mathrm{~mm} / \mathrm{min}$ is to be used up to a CMOD of $0.1 \mathrm{~mm}$, which is to be increased to $0.2 \mathrm{~mm} / \mathrm{min}$ after that until the $\mathrm{CMOD}_{\mathrm{pn}}$ is reached.

The CMOD deformation before unloading $\left(\mathrm{CMOD}_{\mathrm{p}}\right)$ shall reach $\mathrm{CMOD}_{\mathrm{pn}}$ and should not exceed $\mathrm{CMOD}_{\mathrm{pn}}+0.02 \mathrm{~mm}$. The $\mathrm{CMOD}_{\mathrm{pn}}$ value shall be $0.5 \mathrm{~mm}$, which corresponds to the residual stress equal to $f_{\mathrm{R}, 1}$.
Fig. 8 Complete diagram showing the main stages of a creep test

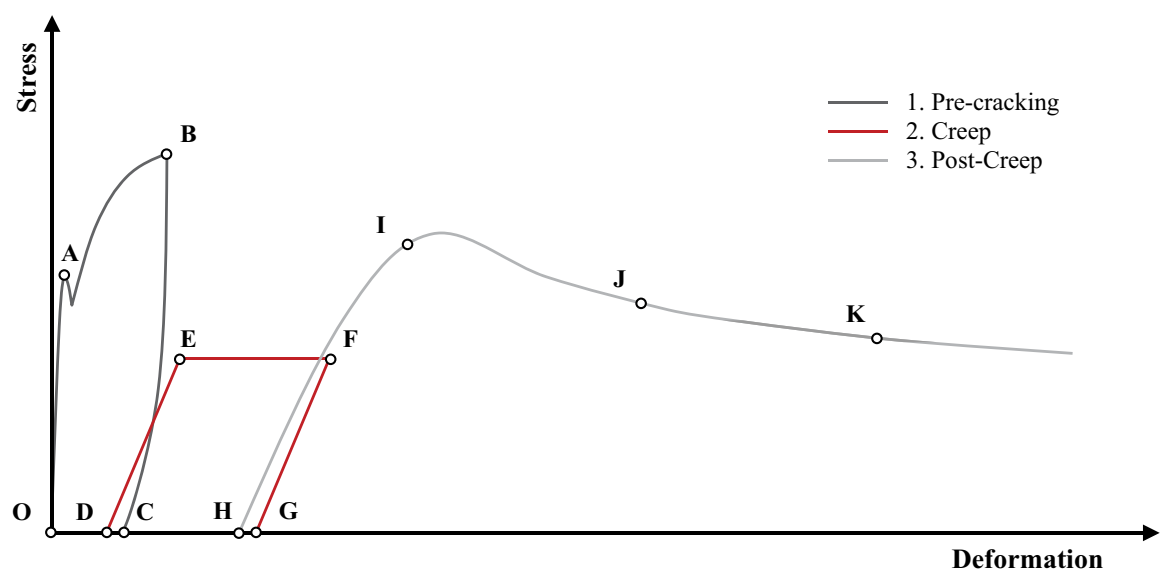


Table 2 Recommended number of specimens to pre-cracked depending on the specimens simultaneously tested per frame

\begin{tabular}{ll}
\hline Specimens per frame & Specimens to be pre-cracked \\
\hline 1 & 1 \\
2 & 4 \\
3 & 5 \\
\hline
\end{tabular}

Once the nominal pre-cracking level $\mathrm{CMOD}_{\mathrm{pn}}$ is achieved, the specimen shall be unloaded immediately at a CMOD rate of $0.2 \mathrm{~mm} / \mathrm{min}$. Once the specimen has been fully unloaded $\left(\mathrm{CMOD}_{\mathrm{pri}}\right)$, the DAS shall remain recording for 10 additional minutes while delayed recovery deformations occur $\left(\mathrm{CMOD}_{\mathrm{pr}}\right)$.

In the case of deflection-controlled testing machine, all the above defined parameters shall be transformed into deflection parameters using the conversion equation in EN 14651.

The parameters to be obtained from the precracking test are defined in Fig. 9. A graphical description is given below for either hardening or softening residual performance.

\subsubsection{Storage after pre-cracking}

Once registered the residual deformation $\mathrm{CMOD}_{\mathrm{pr}}$, the specimen shall be removed from the testing machine and moved into the climate room of the creep test for adapting to the environmental conditions of the longterm test prior to being positioned in the creep frames.

Since the specimens are cracked, they shall be stored supported on their side (turned $90^{\circ}$ ) to avoid

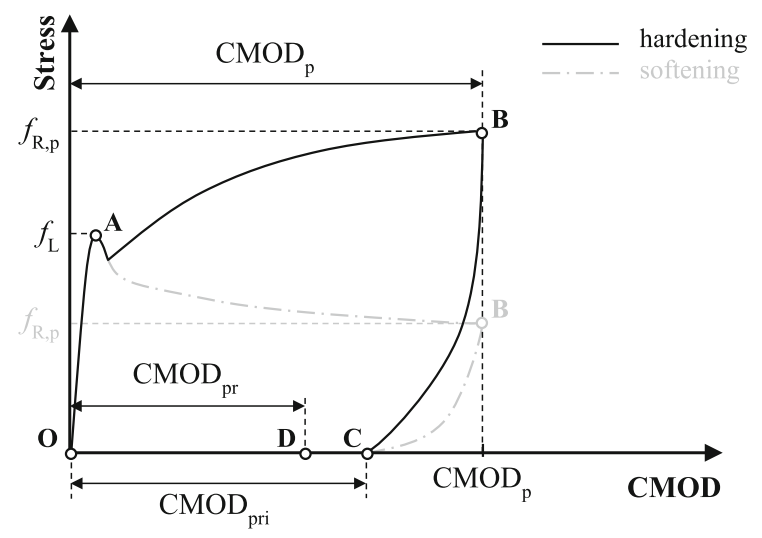

Fig. 9 Pre-cracking stage parameters definition for both hardening and softening behaviour FRC specimens. crack opening deformations due to the self-weight of the specimen.

The transducers shall not be removed from the specimens and shall be conserved in identical position as during the pre-cracking test. If not possible, two DEMEC studs shall be located at both side of the specimen to measure any variation during the storage and positioning.

\subsection{Creep stage}

\subsubsection{Load calibration}

The load shall be adequately controlled during the creep test. It is strongly recommended to place a load cell over the top specimen to assess the load applied. This will allow monitoring the load in each frame and it will help adjust the load if a deviation is noticed at any point. In the case of the lower lever arm setup, the use of a load cell for control is not only recommended but required.

If the upper lever arm setup is used without load cell monitoring, the counterweights load shall be calibrated prior to the positioning of the specimens by placing a load cell at the same location as the specimens. At the end of the creep test, and once the specimens were removed, the counterweights shall be again assessed to assure that there was no load variation during the long-term test duration.

It is recommended to use a class 1 load cell according to EN ISO 7500-1:2018 (relative accuracy error $\pm 1 \%$ ). The load cell capacity shall not be more than five times the applied load.

\subsubsection{Creep index $\left(I_{c}\right)$ or stress level}

The objective of the flexural creep test is to induce a certain level of stress in the cracked FRC specimens. Since both 3PBT and 4PBT load configurations can be used, the expression "load level" can be confusing since the load depends on the load configuration chosen. In consequence, the terminology to be used is either "stress level" or "creep index".

The creep index $\left(I_{\mathrm{c}}\right)$ or stress level is defined as the ratio of applied stress during the creep stage $\left(f_{\mathrm{R}, \mathrm{c}}\right)$ to the residual strength at $\mathrm{CMOD}_{\mathrm{p}}\left(f_{\mathrm{R}, \mathrm{p}}\right)$. In the case of flexural creep test in the cracked state, the service limit state is usually related to $\mathrm{CMOD}_{\mathrm{p}}=0.5 \mathrm{~mm}$. 


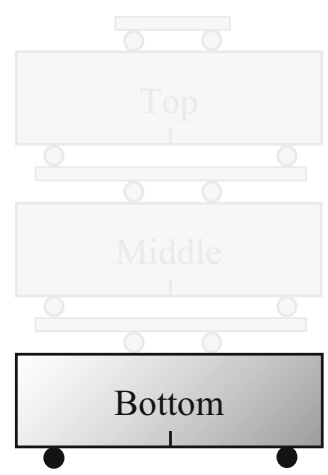

(a)

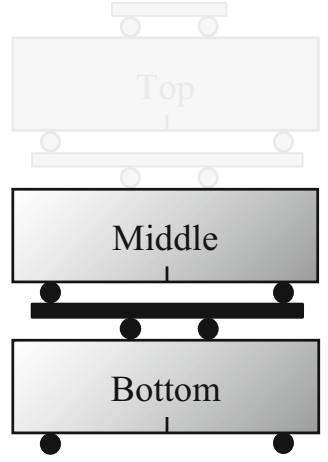

(b)
Fig. 10 Specimens mounting procedure: a locate bottom specimen and reset the first transducer, $\mathbf{b}$ place the transfer plate and the middle specimen and reset the second transducer,

The recommended nominal creep index $\left(I_{\mathrm{c}}\right)$ for the flexural creep test is $50 \%$ of $f_{\mathrm{R}, \mathrm{p}}$ at $\mathrm{CMOD}_{\mathrm{p}}=0.5 \mathrm{~mm}$, which is equal to $50 \%$ of $f_{\mathrm{R}, 1}$.

The acceptable range of variation for the applied stress in this procedure recommendation shall be \pm $5 \%$ of $f_{\mathrm{R}, \mathrm{c}}$. All specimens tested out of the accepted creep index range shall be identified in the test report as tested out of limits.

This creep index recommendation is given as reference for comparison purposes of the long-term behaviour of different FRCs but not as reference related to in-situ creep conditions. On the contrary, if the scientific research at different situations is the purpose of performing this flexure creep test recommended procedure, different creep index values can be adopted.

\subsubsection{Preparation and positioning of test specimens}

Prior to positioning the specimens in the frames, the DAS system shall start recording with the recommended recording rate for loading phase of $1 \mathrm{~Hz}$ (one reading per second) as defined in Sect. 6.3.1.

In the case of the single specimen creep test configuration, the specimen shall be positioned in the frame in the same way as in pre-cracking test. Once the specimen is positioned, the transducer is connected to the DAS, the load cell is placed and centred, and the load is applied.

In the case of the multi-specimen creep test setup, the specimens shall be stacked in a column before the

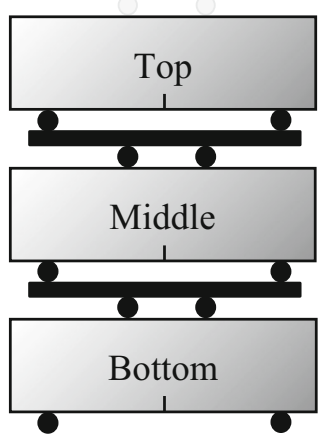

(c)

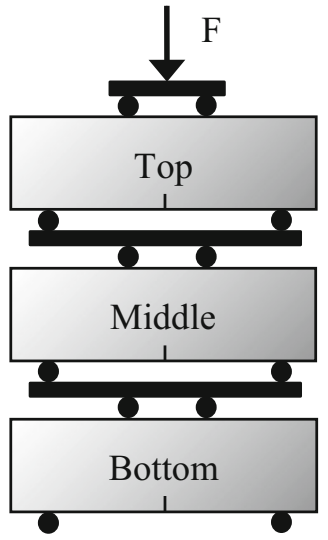

(d) c place the second transfer plate and the top specimen and reset the third transducer, $\mathbf{d}$ finally place the load transfer plate and induce the load into the frame.

load is applied, as depicted in Fig. 10. The mounting of the specimens shall be done step by step. Firstly, the bottom specimen is positioned in the frame, the LVDT transducer is connected to the DAS and the first zero is registered (Fig. 10a). After that, the first transfer plate between specimens and the middle specimen are positioned (Fig. 10b). Since the LVDT of the bottom specimen is already connected, the CMOD deformation due to the weight of the transfer plate and the middle specimens are registered. Once the second LVDT is connected and the second zero registered, the next transfer plate and the top specimen are positioned (Fig. 10c). When the last LVDT is connected and the corresponding zero registered, the column is ready for the loading process to start, as all the specimens in the column are registering CMOD deformations (Fig. 10d). The duration of stacking the specimens shall not exceed $30 \mathrm{~min}$ and the stress induced by the deadload over the bottom specimen when stacked shall not exceeds the $15 \%$ of the expected sustained stress $f_{\mathrm{R}, \mathrm{c}}$.

\subsubsection{Load application}

At the beginning of the creep stage, the load shall be steadily applied at a constant rate, avoiding sudden variations. It is recommended that the load application takes at least $30 \mathrm{~s}$ and no more than $5 \min \left(30 \mathrm{~s}<t_{\text {ci- }}\right.$ $<5 \mathrm{~min}$ ). In the case of the multi-specimen setup, the duration of stacking the specimens shall not exceed $30 \mathrm{~min}$. The stacking time does not count for the $t_{\mathrm{ci}}$ 


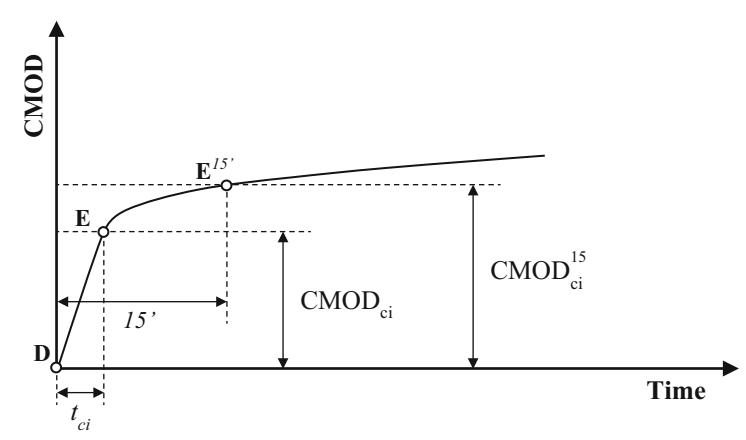

Fig. 11 Instantaneous $\mathrm{CMOD}_{\mathrm{ci}}$ and short-term $\mathrm{CMOD}_{\mathrm{ci}}{ }^{15}$ definition

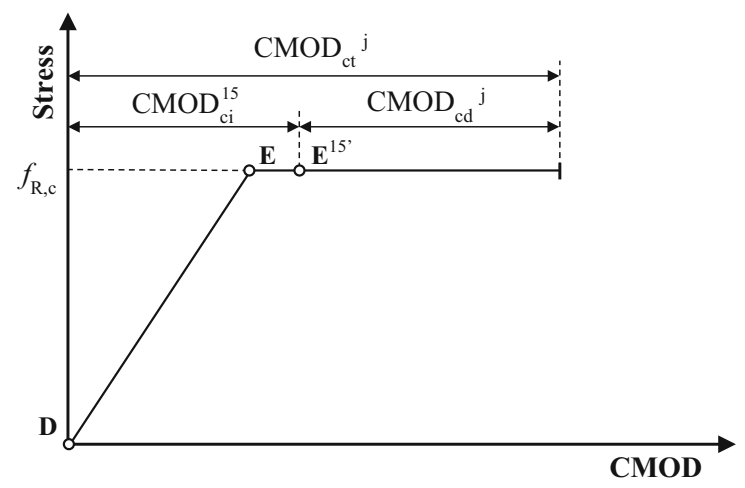

Fig. 12 Creep stage parameters

since the load and deformation caused by the upper specimens are very short.

The instantaneous $\mathrm{CMOD}_{\text {ci }}$ is defined as the CMOD measured once the desired sustained stress $f_{\mathrm{R}, \mathrm{c}}$ is reached. Moreover, this recommendation defines the CMOD value measured $15 \mathrm{~min}$ after the start of the loading process as the short-term deformation $\mathrm{CMOD}_{\mathrm{ci}}{ }^{15}$ as shown in Fig. 11. It is difficult to reach a consensus regarding either instantaneous or short-term deformation shall be considered for the creep coefficient calculation. This recommendation assumes the short-term deformation $\mathrm{CMOD}_{\mathrm{ci}}{ }^{15}$ as reference since it leads to more homogenous creep coefficient values as assessed in the report published by the RILEM Technical Committee 261-CCF [21].

\subsubsection{Test duration and reporting ages}

The recommended minimum time duration of the creep test shall be at least 6 months, but preferably 12 months.
During the long-term test, the DAS recommended recording rate for the CMOD values is one reading every 1800s. If CMOD deformations are manually registered, the minimum recording rate shall be in compliance with the reporting ages requirements. The recommended reporting ages for the total delayed $\mathrm{CMOD}_{\mathrm{ct}}$ are at least at 6 and $12 \mathrm{~h}, 1,2,3,5,7,14,30$ days, and once every 30 days afterwards (that is, $60,90,120$ days and so on) until the end of the creep test.

Temperature and humidity readings shall also be reported at the same reporting ages as the creep deformations.

The typical stress-displacement curve during the creep stage is presented in Fig. 12, where the main parameters of the delayed phase are defined.

\subsubsection{Unloading and storage}

Prior to unloading the specimens, the DAS system shall be switched to the recommended recording rate for unloading phase of $1 \mathrm{~Hz}$ defined in Sect. 6.3.1.

Specimens shall be unloaded once the delayed phase is over, but they shall not be removed from the creep frames for 30 days. During this period, both the elastic and delayed recovery deformations will be measured and recorded as depicted in Fig. 13. The residual elastic deformation $\mathrm{CMOD}_{\text {cri }}$ shall be registered once the lever arm is lifted and the load fully removed. The residual delayed $\mathrm{CMOD}_{\text {crd }}$ after the end of the unloading ramp shall also be recorded at 1, 7, 14 and 30 days after unloading.

The load shall be steadily removed at a constant rate, avoiding sudden changes. It is recommended that the load removal takes at least $30 \mathrm{~s}$ and no more than $5 \mathrm{~min}$. In the case of the multi-specimen setup, only the top load transfer plate shall be removed, but the specimen column shall remain stacked stable without load for 30 days. As described in Sect. 6.2.2, meanwhile the specimens rest stacked, the stress induced to the bottom specimen by deadloads shall not exceed the $15 \%$ of the sustained stress $f_{\mathrm{R}, \mathrm{c}}$, so that the deformations derived from this residual load could be disregarded.

\subsection{Shrinkage test}

The use of shrinkage specimens is recommended to assess the influence in the crack opening due to shrinkage of concrete between measuring points. If we 


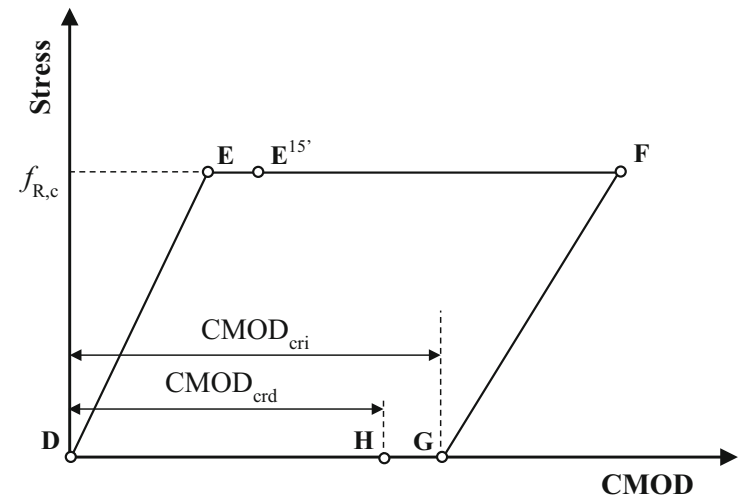

Fig. 13 Unloading phase parameters

consider that clip gauges provide a direct CMOD measure and the distance between measuring points is the notch width, shrinkage should not have any significant effect and thus, shrinkage tests are not necessary but recommended if clip gauges are used.

In those cases where the CMOD is measured with LVDTs according to Fig. 7, concrete shrinkage produces a distance reduction between the measuring points, as illustrated in Fig. 14. In order to consider this effect, shrinkage effect $\left(\mathrm{CMOD}_{\mathrm{cs}}{ }^{\mathrm{j}}\right)$ shall be evaluated by registering the variation in time between the measuring points of a control FRC specimen subjected to no load other than its self-weight. Therefore, at least one control FRC specimen per batch shall be placed in flexure position near the creep frame where the batch is being tested in creep to ensure the same environmental conditions during the shrinkage test.

The size of the specimen shall be the same as the specimens tested in creep and shall be pre-cracked at the same $\mathrm{CMOD}_{\mathrm{pn}}$ as the specimens destined for the creep tests. Shrinkage deformations shall be measured in the same way as creep deformations: the same type of transducer shall be used and placed in the same position as in the creep test specimens. The support boundary conditions for the shrinkage specimens shall be the same as in the creep test. In those cases where the reference measure was deflection instead of CMOD, the same conversion explained in Sect. 6.3.1 shall be done.

Since shrinkage produces a length reduction, the $\mathrm{CMOD}_{\mathrm{cs}} \mathrm{j}$ is a negative value. In order to obtain the real value of $\mathrm{CMOD}_{\mathrm{ct}}{ }^{\mathrm{j}}$, the measured $\mathrm{CMOD}_{\mathrm{ctm}}{ }^{\mathrm{j}}$ shall be corrected by applying the following equation:

$\mathrm{CMOD}_{\mathrm{ct}}^{\mathrm{j}}=\mathrm{CMOD}_{\mathrm{ctm}}^{\mathrm{j}}-\mathrm{CMOD}_{\mathrm{cs}}^{\mathrm{j}}$
As it can be seen in Fig. 15, the real $\mathrm{CMOD}_{\mathrm{ct}}$ becomes higher than measured after the shrinkage correction.

\subsection{Post-creep stage}

The post-creep flexure test shall be performed following the instructions given in the EN 14651 standard in the 3 PBT configuration as used for pre-cracking tests. In the case of a testing machine controlling the CMOD, the test should be performed at a constant CMOD rate of $0.2 \mathrm{~mm} / \mathrm{min}$.

The post-creep bending test will be deemed completed when a CMOD deformation of $4 \mathrm{~mm}$ is reached. After that, the specimen shall be unloaded and there is no need to record any further deformations. When the instrumentation is removed, the specimen shall be split into two halves and the fibres in both faces of the crack shall be counted.

In the case of a testing machine controlling deflection, all the above defined parameters shall be transformed into deflection parameters as explained in EN 14651.

\subsection{Complete diagram for creep test}

Once the curves of the three main stages (precracking, creep and post-creep) are assembled, the post-creep residual strength parameters can be obtained as defined in Fig. 16. If the level of deformation corresponding to $\mathrm{CMOD}_{2}, \mathrm{CMOD}_{3}$ or $\mathrm{CMOD}_{4}$ is reached during the creep stage, the corresponding residual strength shall not be considered in the report.

\subsection{Fibre counting}

After the post-creep bending test, the specimens shall be split into two halves and the fibres crossing the cracked section be counted. Three different regions (top, middle and bottom) with equal area shall be considered in both faces of the cracked section as depicted in Fig. 17. The number of fibres in each region shall be counted and in the case of broken fibres, it is recommended to count only the broken fibres from one of the sides.

The number of fibres $n_{f}$ shall be reported in fibres/ $\mathrm{cm}^{2}$ for each region and face. The fibre density should be similar in all areas for homogeneous behaviour but 


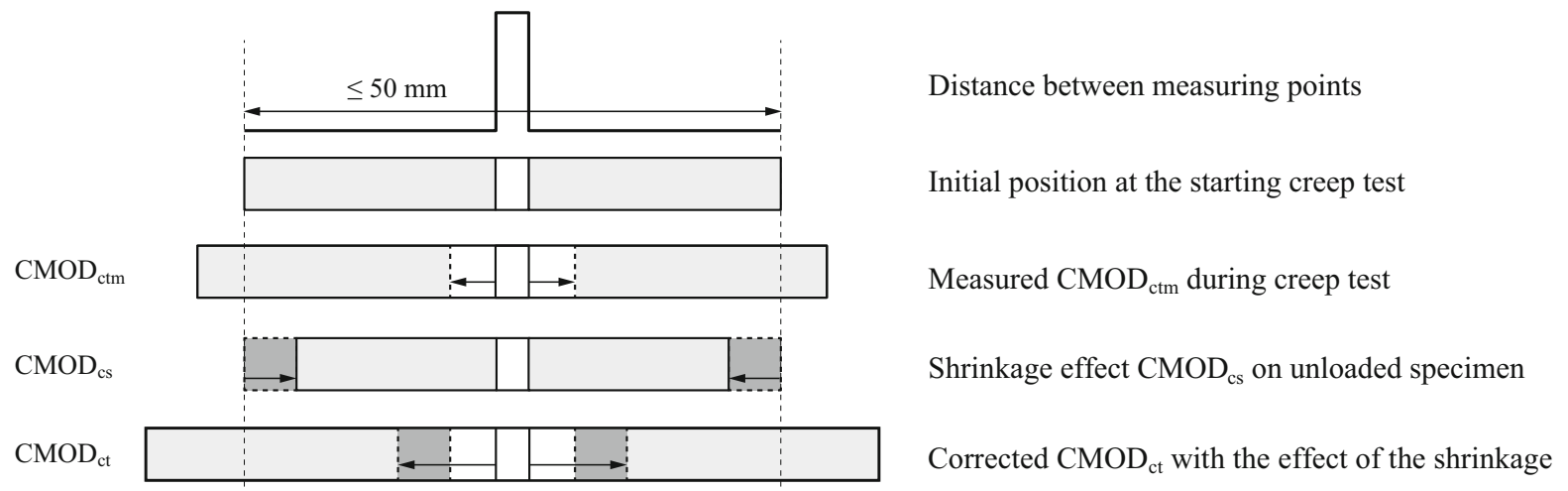

Fig. 14 Consideration of shrinkage deformations
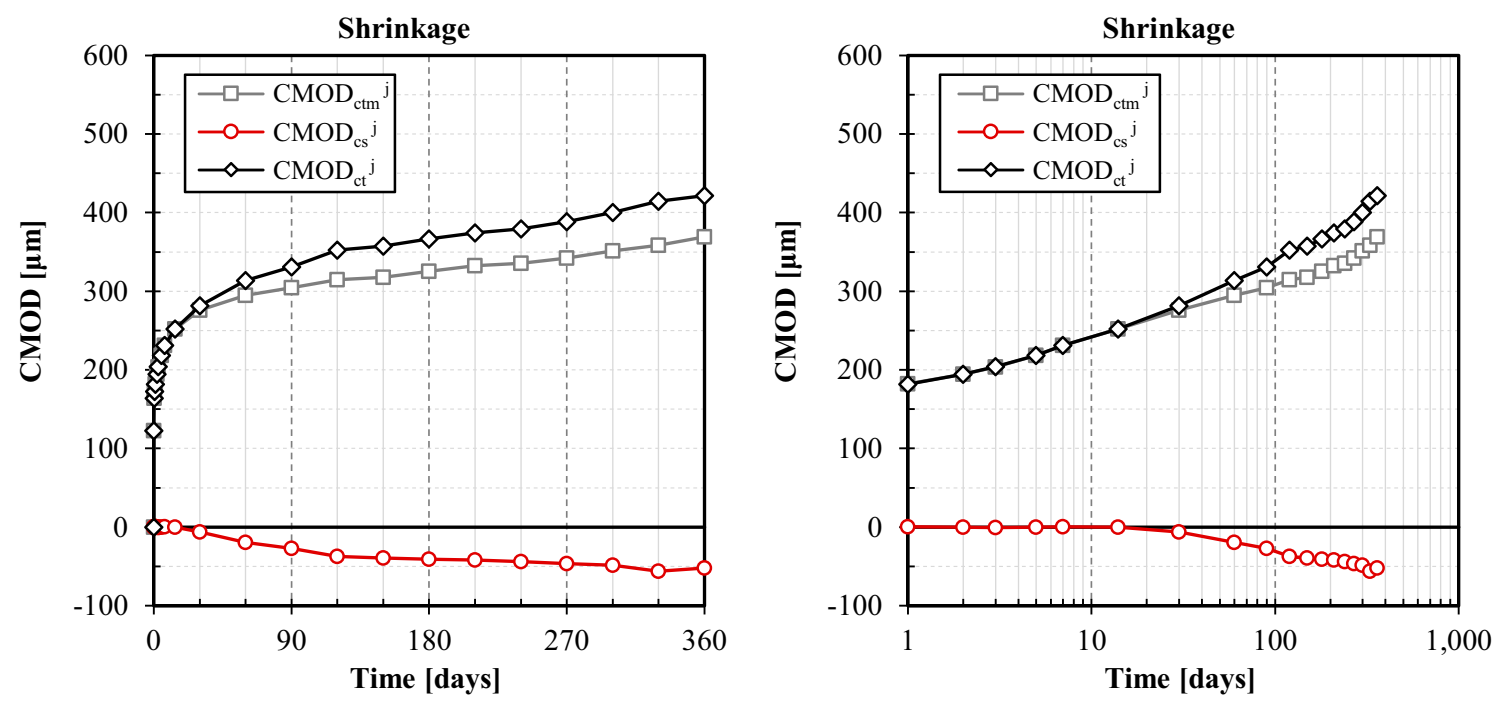

Fig. 15 Example of delayed CMOD deformation correction considering shrinkage

sometimes the distribution of fibres is not as homogeneous as expected. This parameter could help to explain any atypical behaviour during creep test if the distribution of fibres is not homogeneous.

\section{Evaluation of test results}

\subsection{Delayed deformations}

Delayed deformations shall be represented as CMODtime curves, as seen in Fig. 18. This representation is the first step in the evaluation of the creep test results. Since the creep curve follows a logarithmic trend, delayed deformations shall be represented against both linear and logarithmic axes. The vertical axis shall represent the CMOD deformations, in microns. In the case of linear representation of time, the horizontal axis shall be divided in 30 days periods, to coincide with the reporting ages. In the case of logarithmic time representation, the horizontal axis shall be divided in decimal logarithm from 1 to 1000 days.

\subsection{Residual performance after creep test}

The complete diagram of the residual performance comprising the three stages of the creep test shall be depicted for each specimen. The residual performance obtained on each stage of the creep test shall be mounted in a Stress-CMOD curve as explained in Sect. 7.5. The 


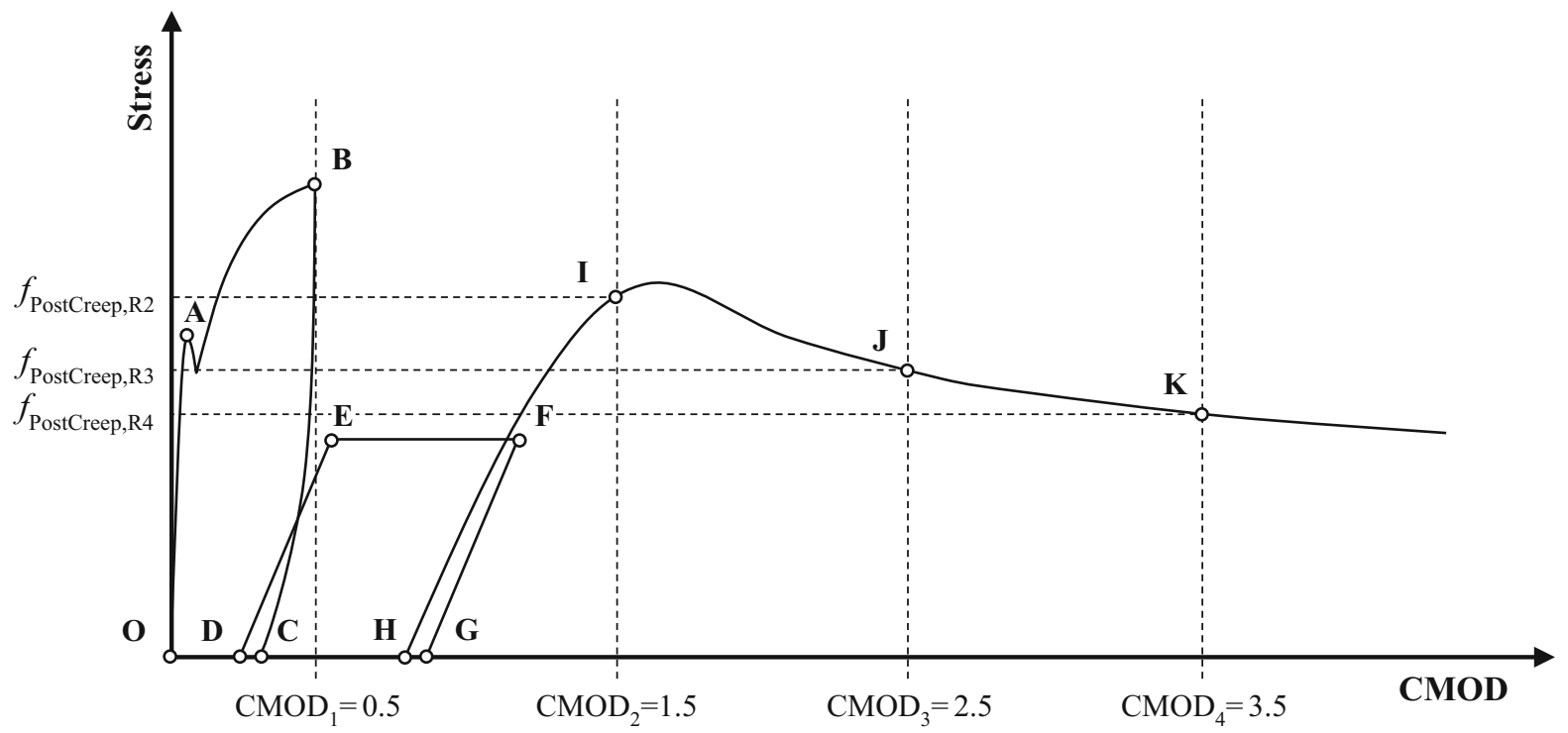

Fig. 16 Post-creep stage parameters

Fig. 17 Example of faces division in three areas and fibres location

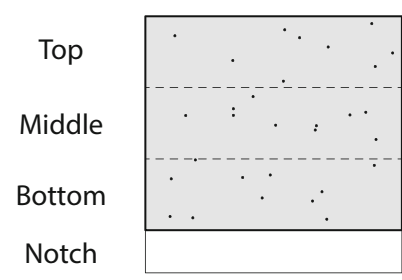

Face $\mathrm{A}$

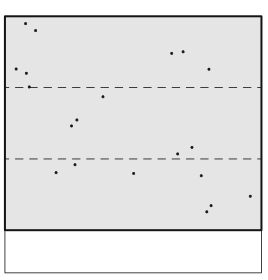

Face B

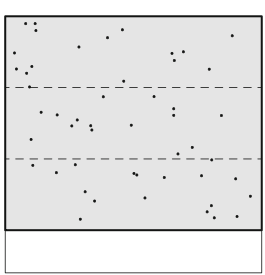

Faces $\mathrm{A}+\mathrm{B}$ vertical axis shall represent the Stress in MPa whereas the horizontal axis shall represent the CMOD deformation in microns as illustrated in the Fig. 19 sample.

This representation serves to obtain the different residual flexural tensile post-creep strengths as well as to compare the residual performance of the specimens tested in creep to those specimens of the characterization tests.

\subsection{Environmental conditions}

The temperature and humidity readings shall be given in the report at the same reporting ages as for creep deformations.

A figure with the evolution of both temperature and relative humidity over time during the creep test duration with two readings per day (day/night) shall be included in the test report, as illustrated in Fig. 20. Furthermore, all unusual temperature or relative humidity deviations shall be reported.

\subsection{Creep coefficients}

The long-term performance can be evaluated by means of the creep coefficients, defined as the ratio of the delayed deformation at certain time $\left(\mathrm{CMOD}_{\mathrm{cd}}{ }^{\mathrm{j}}\right)$ to the short-term deformation $\left(\mathrm{CMOD}_{\mathrm{ci}}{ }^{15}\right)$ as defined in Sect. 7.2.4. Since the short-term deformations can refer to both the start of the creep stage and the origin of deformations, two different creep coefficients can be obtained analogously.

The creep coefficients can be obtained for all the reporting ages, but the following times are recommended as reference for the creep coefficients for the first year of creep test: 30, 90, 180 and 360 days. After the first year, one additional creep coefficient by year shall be calculated. The evolution in time of the creep coefficient can be represented by a fitted power-law line. 

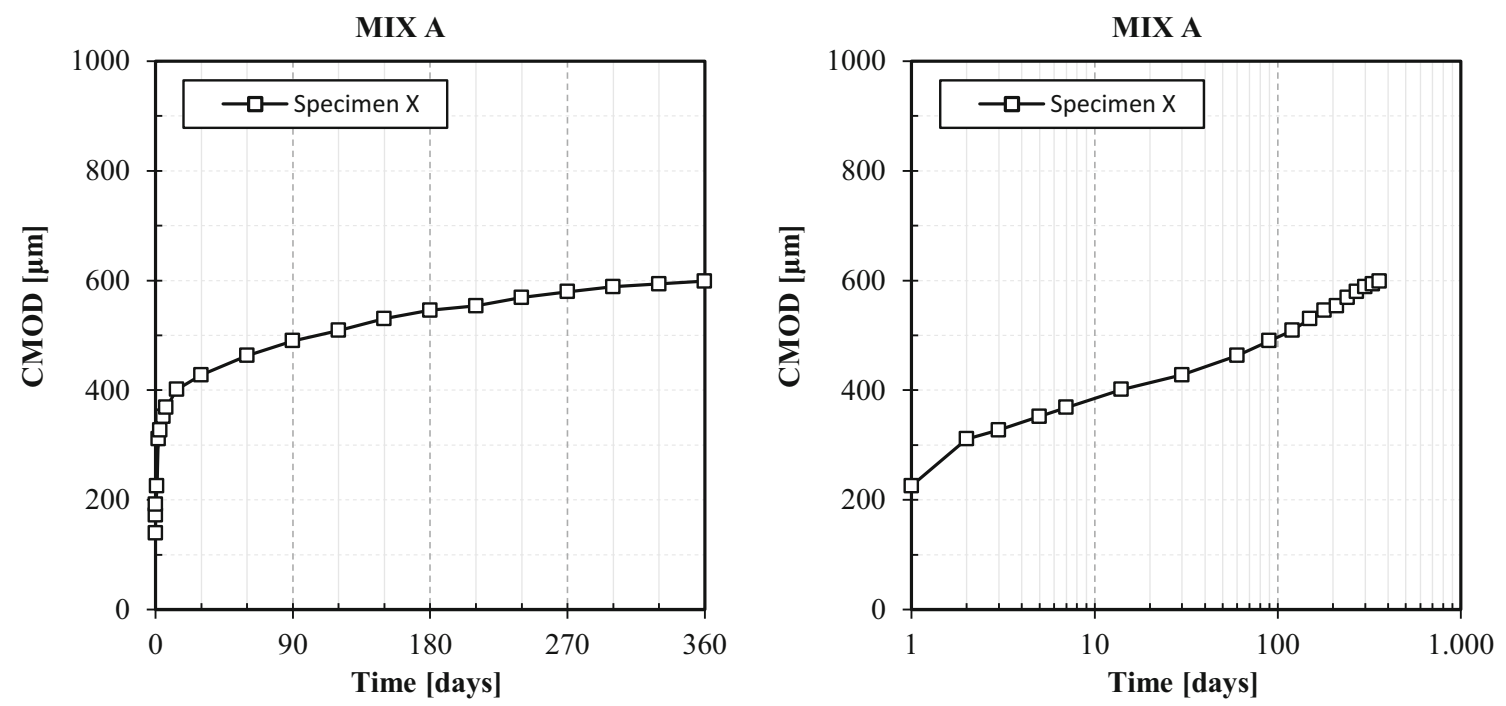

Fig. 18 Example CMOD-Time results presentation for creep tests of a FRC specimen

\subsubsection{Creep coefficient referred to the creep stage}

The creep coefficient referred to the creep stage only considers the deformations during the creep stage, and thus, the short-term deformation $\mathrm{CMOD}_{\mathrm{ci}}{ }^{15}$ value measured $15 \mathrm{~min}$ after the start of the loading process, is considered as reference. The creep coefficient referred to the creep stage is obtained by means of the following equation:

$$
\begin{aligned}
\varphi_{w, c}^{j} & =\mathrm{CMOD}_{c d}^{j} / \mathrm{CMOD}_{c i}^{15} \\
& =\left(\mathrm{CMOD}_{c t}^{j}-\mathrm{CMOD}_{c i}^{15}\right) / \mathrm{CMOD}_{c i}^{15}
\end{aligned}
$$

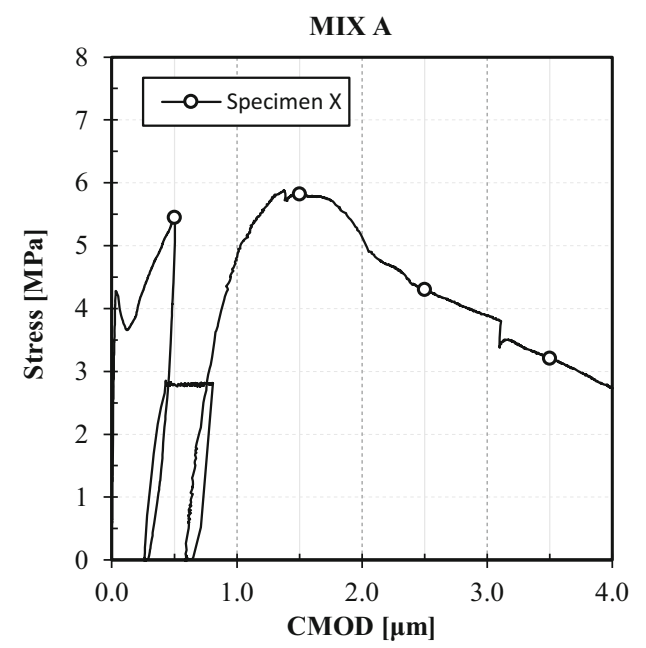

Fig. 19 Example of Stress-CMOD presentation for the whole creep test stages of a FRC specimen

\subsubsection{Creep coefficient referred to the origin of deformation}

The creep coefficient referred to the origin of deformations refers to the original uncracked state of the specimen. Therefore, the residual pre-crack recovery $\mathrm{CMOD}_{\mathrm{pr}}$ shall be added to the short-term deformation $\mathrm{CMOD}_{\mathrm{ci}}{ }^{15}$ to obtain the absolute short-term deformation to origin $\mathrm{CMOD}_{\mathrm{oi}}{ }^{15}$. The creep coefficient

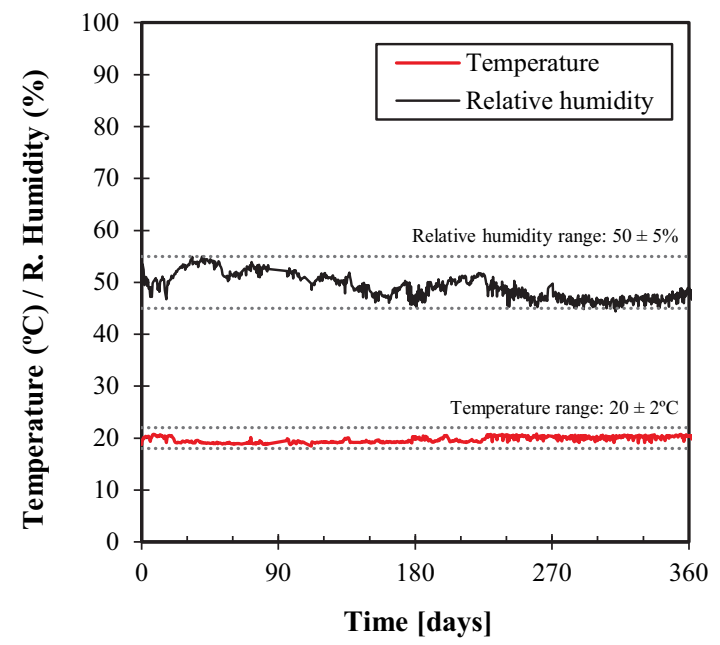

Fig. 20 Example of reported figure for temperature and relative humidity evolution 
referred to the origin of deformations is obtained by means of the following equation:

$$
\begin{aligned}
\varphi_{w, o}^{j} & =\mathrm{CMOD}_{c d}^{j} / \mathrm{CMOD}_{o i}^{15} \\
& =\left(\mathrm{CMOD}_{c t}^{j}-\mathrm{CMOD}_{c i}^{15}\right) /\left(\mathrm{CMOD}_{p r}+\mathrm{CMOD}_{c i}^{15}\right)
\end{aligned}
$$

\section{Test report}

All the testing details that deviate from this recommendation shall be reported.

Results shall be provided for each specimen. Mean, standard deviation and coefficient of variation of each parameter should also be calculated for the set of specimens.

The test report shall include at least the following information:

- Explicit reference to this testing recommendation

- Origin and indication reference of the test specimens

- Concrete mix properties:

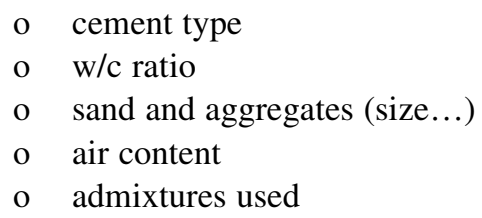

- Origin, material of the fibres and geometrical and mechanical properties:
o length
o diameter
o aspect ratio
o tensile strength
o Young's modulus

- Environmental conditions during creep test: temperature in ${ }^{\circ} \mathrm{C}$ and relative humidity in $\%$.

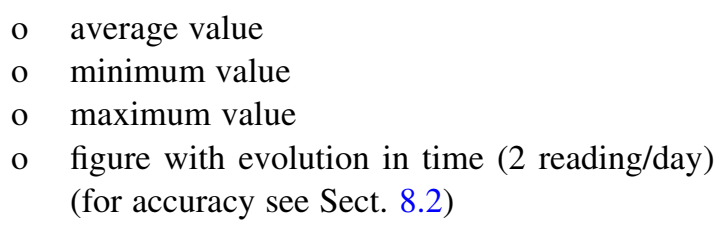

- Specimen properties:

o specimen dimensions $b, h, h_{\mathrm{sp}}$ and $l$

o notch dimensions (height and width) o specimen age at the time of notching (in days)

o specimen age in the pre-cracking (in days)

o specimen age at the beginning of creep test (in days)

- Pre-cracking test data:

o pre-cracking test load configuration (3PBT or 4PBT)

o dimensions related to the load configuration (support $\operatorname{span} l, l_{\mathrm{a}}, l_{\mathrm{b}}$ )

o residual flexural tensile strength at the limit of proportionality $\left(f_{\mathrm{L}}\right)$

o residual flexural tensile strength at $\mathrm{CMOD}_{\mathrm{p}}$ $\left(f_{\mathrm{R}, \mathrm{P}}\right)$

o load at $\operatorname{LOP}\left(\mathrm{F}_{\mathrm{L}}\right)$

o load at $\mathrm{CMOD}_{\mathrm{p}}\left(\mathrm{F}_{\mathrm{R}, \mathrm{P}}\right)$

o reference displacement registered during test (CMOD or deflection)

o target nominal CMOD in the pre-cracking stage $\left(\mathrm{CMOD}_{\mathrm{pn}}\right)$

o maximum CMOD reached in the pre-cracking stage $\left(\mathrm{CMOD}_{\mathrm{p}}\right)$

o elastic CMOD recovery after unloading in the pre-cracking stage $\left(\mathrm{CMOD}_{\mathrm{pri}}\right)$

o residual CMOD 10 min after unloading in the pre-cracking stage $\left(\mathrm{CMOD}_{\mathrm{pr}}\right)$

o number of cracks that starts from the tip of the notch

- Creep test data and parameters:

o creep test load configuration (3PBT or 4PBT)

o dimensions related to the load configuration (support $\operatorname{span} l, l_{\mathrm{a}}, l_{\mathrm{b}}$ )

o number of specimens in the creep frame

o location/position in the creep frame

o duration of creep tests (in days)

o nominal creep index $\left(I_{\mathrm{n}}\right)$

o stress applied during the creep stage $\left(f_{\mathrm{R}, \mathrm{c}}\right)$

o load applied during the creep stage $\left(\mathrm{F}_{\mathrm{c}}\right)$

o real creep index applied $\left(I_{\mathrm{c}}\right)$

o time duration of the loading process in the creep test $\left(t_{\mathrm{ci}}\right)$

o instantaneous CMOD immediately after reaching the reference load $\left(\mathrm{CMOD}_{\mathrm{ci}}\right)$

o short-term CMOD value 15 min after start loading the specimen $\left(\mathrm{CMOD}_{\mathrm{ci}}{ }^{15}\right)$

o total $\mathrm{CMOD}_{\mathrm{ct}}{ }^{\mathrm{j}}$ at $\mathrm{j}$ days (where the reporting ages $j$ are defined in 7.2.5) corrected by shrinkage if required 
o elastic CMOD recovery after unloading the creep test $\left(\mathrm{CMOD}_{\text {cri }}\right)$

o delayed $\mathrm{CMOD}_{\text {crd }}$ recovery after unloading the creep test (at reporting ages defined in 7.2.6)

o figure with CMOD-Time evolution during the creep stage (as defined in 0 ).

- Post-creep test data:

o residual flexural tensile strength corresponding to origin at CMOD2 $=1.5 \mathrm{~mm}$

o residual flexural tensile strength corresponding to origin at CMOD3 $=2.5 \mathrm{~mm}$

o residual flexural tensile strength corresponding to origin at CMOD4 $=3.5 \mathrm{~mm}$

o figure with Stress-CMOD residual performance during the three stages of creep test (as defined in 0).

- Fibre counting data:

o fibre density in fibres $/ \mathrm{cm}^{2}$ of the three areas of both sides

- Creep coefficients at reporting ages defined in 8.4

Acknowledgements This recommendation was prepared by a working group within RILEM TC 261-CCF based on the results and conclusions obtained from a Round-Robin Test in which nineteen international laboratories were involved. The contribution of all TC members in the preparation, final reading and approval of this recommendation are gratefully acknowledged.

\section{Declarations}

Conflict of Interest The authors declare that they have no conflict of interest.

Open Access This article is licensed under a Creative Commons Attribution 4.0 International License, which permits use, sharing, adaptation, distribution and reproduction in any medium or format, as long as you give appropriate credit to the original author(s) and the source, provide a link to the Creative Commons licence, and indicate if changes were made. The images or other third party material in this article are included in the article's Creative Commons licence, unless indicated otherwise in a credit line to the material. If material is not included in the article's Creative Commons licence and your intended use is not permitted by statutory regulation or exceeds the permitted use, you will need to obtain permission directly from the copyright holder. To view a copy of this licence, visit http://creativecommons.org/licenses/by/4.0/.

\section{References}

1. Theodorakopoulos D (1995) Creep characteristics of glass reinforced cement under flexural loading. Cement Concr Compos 17:267-279

2. Chanvillard G, Roque O (1999) Behaviour of fibre reinforced concrete cracked section under sustained load. High Performance Fiber Reinforced Cement Composites (HPFRCC 3) Mainz, Germany, pp 239-250, RILEM PRO 06

3. Kurt S, Balaguru P (2000) Post crack creep of polymeric fibre-reinforced concrete in flexure. Cem Concr Res 30(2):183-190

4. Mackay J, Trottier JF (2004) Post-crack behavior of steel and synthetic FRC under flexural creep. In: Shotcrete, Proc. 2nd Intnl. Conf. on Engineering, Cairns, Australia (2004), pp 183-192

5. Kusterle W (2009) Viscous material behaviour of solidscreep of polymer fibre reinforced concrete. In: Proc. 5th Central European Congress on Concrete Engineering. obv, Baden, pp 95-100

6. Arango S, Serna P, Martí-Vargas JR, García-Taengua E (2012) A test method to characterize flexural creep behaviour of pre-cracked FRC specimens. Exp Mech 52(8):1067-1078

7. Zerbino RL, Barragan BE (2012) Long-term behaviour of cracked steel fibre-reinforced concrete beams under sustained loading. ACI Mater J 109(2):215-224

8. Abrishambaf A, Barros JAO, Cunha VMCF (2015) Timedependent flexural behaviour of cracked steel fibre reinforced self-compacting concrete panels. Cem Concr Res 72:21-36

9. Buratti N, Mazzotti C (2016) Experimental tests on the long-term behaviour of SFRC and MSFRC in bending and direct tension. In: Proceedings of the BEFIB 2016, 9th RILEM international symposium on fiber reinforced concrete, pp. 163-174, Vancouver, Canada, 19-21 Sept 2016

10. Babafemi AJ, Boshoff WP (2015) Tensile creep of macrosynthetic fibre reinforced concrete (MSFRC) under uniaxial tensile loading. Cement Concr Compos 55:62-69

11. Vrijdaghs R, di Prisco M, Vandewalle L (2018) Uniaxial tensile creep of a cracked polypropylene fiber reinforced concrete. Mater Struct 51:5. https://doi.org/10.1617/ s11527-017-1132-5

12. Vasanelli E, Micelli F, Aiello MA, Plizzari G (2013) Long term behaviour of FRC flexural beams under sustained load. Eng Struct 56:1858-1867

13. Bernard ES (2010) Influence of fibre type on creep deformation of cracked fibre-reinforced shotcrete panels. ACI Mater J 107(5):474-480

14. EFNARC (2012) Testing sprayed concrete-Creep test on square panel

15. Larive C, Rogat D, Chamoley D, Regnard A, Pannetier T, Thuaud C (2016) Influence of fibres on the creep behaviour of reinforced sprayed concrete. In: Proceedings of ITA World Tunnel Congress WTC 2016, April 22-28, San Francisco, United States

16. Monetti DH, Llano-Torre A, Torrijos MC, Giaccio G, Zerbino R, Martí-Vargas JR, Serna P (2019) Long-term behavior of cracked fiber reinforced concrete under service 
conditions. Construct Build Mater; 196:649-658. https:// doi.org/10.1016/j.conbuildmat.2018.10.230

17. Llano-Torre A., Martí-Vargas JR, Serna P (2020) Flexural and compressive creep behavior of UHPFRC specimens. Construct Build Mater; 244:118254. https://doi.org/10. 1016/j.conbuildmat.2020.118254

18. Serna P, Llano-Torre A and Cavalaro S H P (ed) (2017) Creep behaviour in cracked sections of fibre reinforced concrete: proceedings of the international RILEM Workshop FRC-CREEP 2016. RILEM bookseries 14 (Dordrecht: Springer)

19. Llano-Torre A, Serna P, Cavalaro SHP (2016) International round robin test on creep behavior of FRC supported by the RILEM TC 261-CCF. In: Proceedings of the BEFIB 2016, 9th RILEM international symposium on fiber reinforced concrete, pp 127-140, Vancouver, Canada, 19-21 Sept 2016

20. Serna P, Llano-Torre A, García-Taengua E, Martí-Vargas JR (2015) Database on the long-term behaviour of FRC: a useful tool to achieve overall conclusions. In: Proceedings of the 10th international conference on mechanics and physics of Creep, Shrinkage, and Durability of Concrete and Concrete Structures, Vienna, September 2015, pp 1544-1553

21. Llano-Torre A., Serna P. (eds) Round-Robin test on creep behaviour in cracked sections of FRC: experimental program, results and database analysis. RILEM State-of-theArt Reports. Springer. https://doi.org/10.1007/978-3-03072736-9

22. ASTM International (2015) C1812/C1812M-15e1 Standard Practice for Design of Journal Bearing Supports to be Used in Fiber Reinforced Concrete Beam Tests. West Conshohocken, PA; ASTM International. https://doi.org/10. 1520/C1812_C1812M-15E01

Publisher's Note Springer Nature remains neutral with regard to jurisdictional claims in published maps and institutional affiliations. 